\title{
Properties Study of SILAR Deposited Cobalt Selenide Thin Films
}

\author{
Ho Soonmin
}

Centre for American Education, INTI International University Putra Nilai,71800, Negeri Sembilan, Malaysia.

\begin{abstract}
Thin films are attractive materials to be used in laser, solar cells, sensors, phosphors, light emitting diodes, IR windows and flat panel displays. Several deposition methods have been employed to deposit thin films as reported by many researchers. In this report, the cobalt selenide thin films have been deposited onto microscope glass slide via successive ionic layer adsorption and reaction method. This deposition method is a simple method owing to the inexpensive technique and can produce films at a low bath temperature. All the samples were investigated by using XRD, FESEM and UVvisible spectrophotometer. The XRD pattern confirmed that cubic phase cobalt selenide thin films. The FESEM image exhibited that the obtained sample is dense, uniform, and smooth surface.
\end{abstract}

Key Words: XRD, FESEM, Thin films, Cobalt selenide, SILAR technique, Semiconductor, Band gap

\section{INTRODUCTION}

Researcher highlighted that thin film deposition is the process of depositing thin film coatings onto various types of substrates [1-3]. It is considered as very important step in the synthesis of several opto-electronic [4-6], solid state and medical devices. The obtained films showed some unique properties such as high dielectric constant, excellent absorption coefficient [7-9], good refractive index, and wide band gap [10-12]. Several deposition techniques were used to produce thin films including SILAR method, Solvo thermal technique [13], pulsed laser deposition [14], vacuum evaporation [15], electron beam evaporation, molecular beam epitaxy, radio frequency sputtering [16], atomic layer deposition [17], chemical vapour deposition, chemical bath deposition [18-20], electro deposition [21-23] and spray pyrolysis. Physical properties of the deposited films have been characterized by X-ray diffractometry, Fourier transform infrared spectroscopy [24], reflection high-energy electron diffraction [25], Field emission scanning electron microscopy [26], Atomic force microscopy A(FM), Raman spectroscopy [27], Transmission electron microscopy [TEM], Scanning probe microscopy [28], X-ray photoelectron spectroscopy [29], Energy Dispersive XRay Analysis and spectroscopic ellipsometry [30].

One of the chemical deposition methods, is called successive ionic layer adsorption and reaction (SILAR) technique, was employed for making large area thin film onto substrate [31]. During the deposition process, the cleaned substrate will be immersed into cationic precursor solution [32] and anionic precursor solution, respectively. In between the cation and anion immersions, the substrate is rinsed with distilled water also in order to remove undesired materials onto the surface of substrate [33]. This deposition technique offers several advantages to researcher including convenient for large area deposition at low temperature [34], starting materials used are commonly available [35], can control the film thickness, simple and low cost deposition method [36].

Cobalt was observed in some minerals such as erythrite, cobaltite and 
skutterudite. It is one of the transition elements, with atomic number " 27 " and chemical symbol "Co". The production of cobalt was 79900 metric tons in 2008 (Table 1). The cobalt can be used to produce drying agents for paints, lithium ion battery, high strength alloys, catalyst for the petroleum, airbags in automobile industry. The global production reached 140000 in metric tons in 2020. Selenium was found in the soil, water and some foods. Selenium is a non-metal with the chemical symbol "Se", and atomic number of " 34 ". The table 2 showed the refinery production global of selenium from 2009 until 2017. The obtained data indicated a minor increase in production from 2009 (2.16 million $\mathrm{kg}$ ) to 2017 (2.71 million kg).

Table 1: Worldwide mine production of cobalt from 2008 to 2020 [37]

\begin{tabular}{|c|c|}
\hline Year & Production (in metric tons) \\
\hline 2008 & 79900 \\
\hline 2009 & 79900 \\
\hline 2010 & 107000 \\
\hline 2011 & 110000 \\
\hline 2012 & 103000 \\
\hline 2013 & 110000 \\
\hline 2014 & 123000 \\
\hline 2015 & 126000 \\
\hline 2016 & 123000 \\
\hline 2017 & 120000 \\
\hline 2018 & 148000 \\
\hline 2019 & 144000 \\
\hline 2020 & 140000 \\
\hline
\end{tabular}

Table 2: Refinery production global of selenium from 2009 until 2017 [38]

\begin{tabular}{|c|c|}
\hline Year & Production \\
\hline 2009 & $2160000 \mathrm{~kg}$ \\
\hline 2010 & $2150000 \mathrm{~kg}$ \\
\hline 2011 & $2180000 \mathrm{~kg}$ \\
\hline 2012 & $2260000 \mathrm{~kg}$ \\
\hline 2013 & $2280000 \mathrm{~kg}$ \\
\hline 2014 & $2470000 \mathrm{~kg}$ \\
\hline 2015 & $2660000 \mathrm{~kg}$ \\
\hline 2016 & $2800000 \mathrm{~kg}$ \\
\hline 2017 & $2710000 \mathrm{~kg}$ \\
\hline
\end{tabular}

The objective of this work is to report the properties of cobalt selenide thin films deposited onto glass substrate under specific experimental conditions. The properties of films were investigated by using XRD (x-ray diffraction), FESEM and UV-visible spectrophotometer.

\section{MATERIALS AND METHODS}

Chemical such as cobalt (II) chloride hexahydrate $\left(\mathrm{CoCl}_{2} \cdot 6 \mathrm{H}_{2} \mathrm{O}\right)$ and sodium selenite (Na2O3Se) were used without further purification in this work. The substrate (microscope glass slide) was chosen, washed by acetone, and de-ionized water before use. During the experiment, the cleaned substrate was immersed in the cationic solution $\left(0.2 \mathrm{M}\right.$ of $\mathrm{Co}^{2+}$ ion) for 30 seconds. Then, rinsing with de-ionized water for 10 seconds. Following that, the substrate was immersed in anionic solution $\left(0.2 \mathrm{M}\right.$ of $\mathrm{Se}^{2-}$ ions) for 30 seconds. Finally, rinsing with de-ionized water for another 10 seconds. The deposition process was carried out at room temperature, by using 15 cycles.

The X-ray diffraction was used to study the structure of the film. The Malvern Panalytical diffractometer (EMPYREAN) equipped with a $\mathrm{Cu} \mathrm{K} \alpha(\lambda=0.15418 \mathrm{~nm})$ radiation source was used. The data were analyzed by step scanning from $10^{\circ}$ to $80^{\circ}$ with a step size of $0.02^{\circ}(2 \theta)$. The field emission scanning electron microscope (FEI, Nova Nanosem 230) was employed for the characterization of the morphology of films. The Perkin Elmer UV/Vis Lambda 35 Spectrophotometer was utilized in order to study the optical properties and band gap energy value of obtained films.

\section{RESULTS AND DISCUSSION}

The field emission scanning electron microscope (FESEM) gives topographical and elemental information at various magnifications [39]. Many researchers highlighted that FESEM can provide clearer and less electrostatically distorted images [40] if compared to scanning electron microscopy. The FESEM image of SILAR deposited thin films at 15 cycles as shown in figure 1. The FESEM image confirmed that the obtained films were dense, smooth surface, full coverage to the surface of substrate with the grain size varies from 1$2.5 \mu \mathrm{m}$. 


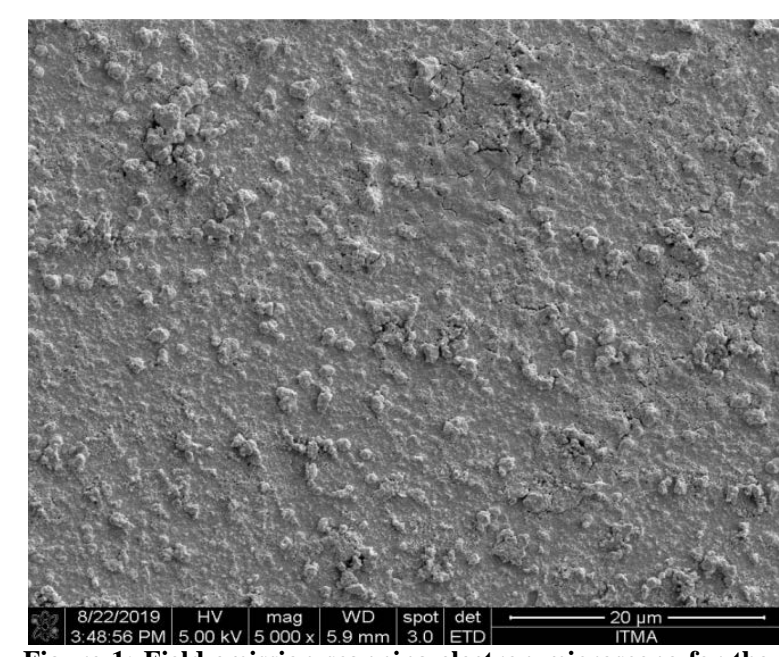

Figure 1: Field emission scanning electron microscope for the cobalt selenide thin films

The x-ray diffraction is a very fast analytical method [41] employed for phase identification of crystalline materials in different fields such as material science [42], environmental science, geology, biology and engineering. Figure 2 exhibited the X-ray diffraction pattern for the cobalt selenide thin films prepared under specific conditions. Based on the results, diffraction peak was attributed to (111) plane, and matched the standard Joint Committee on Powder Diffraction Standards (Reference code: 98-004-4857). The lattice parameter values are $\mathrm{a}=\mathrm{b}=\mathrm{c}=10.431 \AA$.

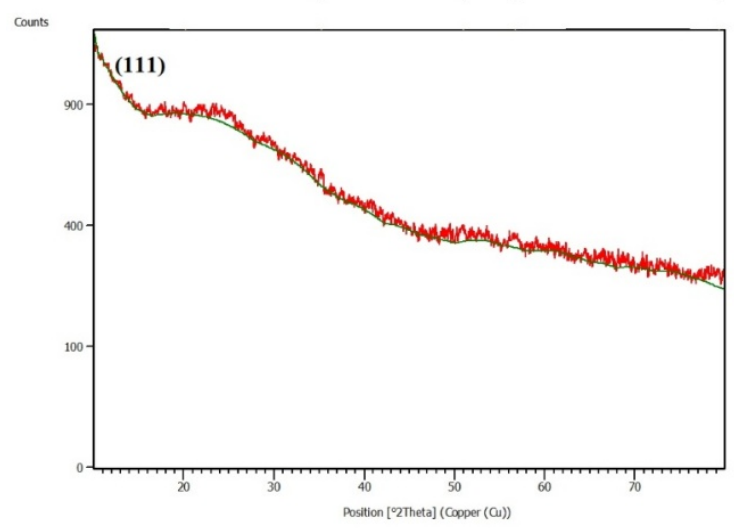

Figure 2: X-ray diffraction pattern for the cobalt selenide thin films

The UV-visible spectroscopy is employed to study how much substance absorbs light during the experiment [43]. This process will be carried out by measuring the intensity of light [44] that passes through thin film with respect to the intensity of light via reference sample (glass slide). Figure 3 indicated the UV-visible absorption spectrum in the wavelength regions of 300 to $1000 \mathrm{~nm}$. The obtained films exhibited high absorbance value because of these films showed the smooth and homogeneous surface topography. The band gap was calculated based on the Stern equation.

$$
A=\frac{\left[k\left(h v-E_{g}\right)^{n / 2}\right.}{h v}[\text { Equation 1] }
$$

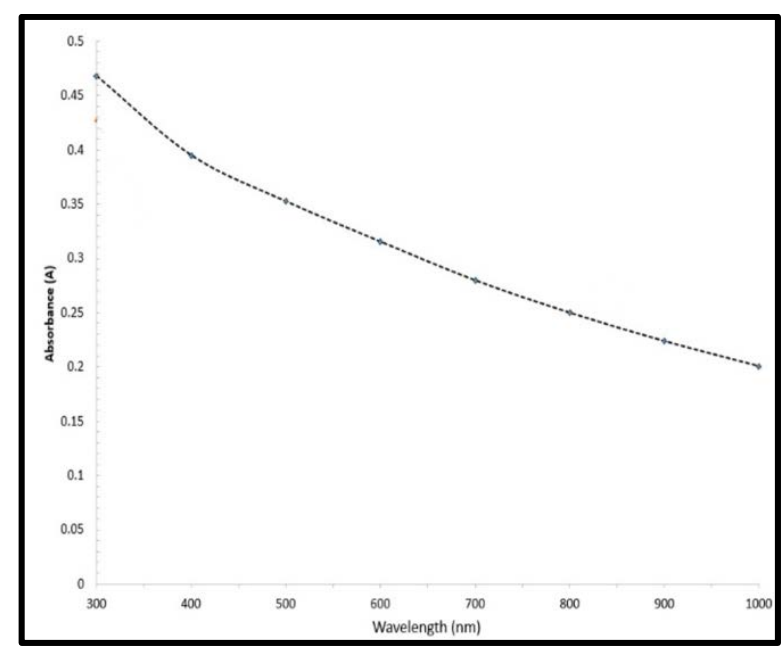

Figure 3: Optical absorbance spectrum of cobalt selenide thin films

where $v$ is the frequency, $h$ is the Planck's constant, $k$ equals a constant while $n$ carries the value of either 1 or 4 . The $n$ value is 1 for a direct gap material and 4 for indirect gap material. The figure 4 exhibited the plot of $(A h v)^{2}$ against $h v$. The extrapolation of this straight line will intercept the $h v$-axis to produce the band gap value. The band gap value to be $2.1 \mathrm{eV}$.

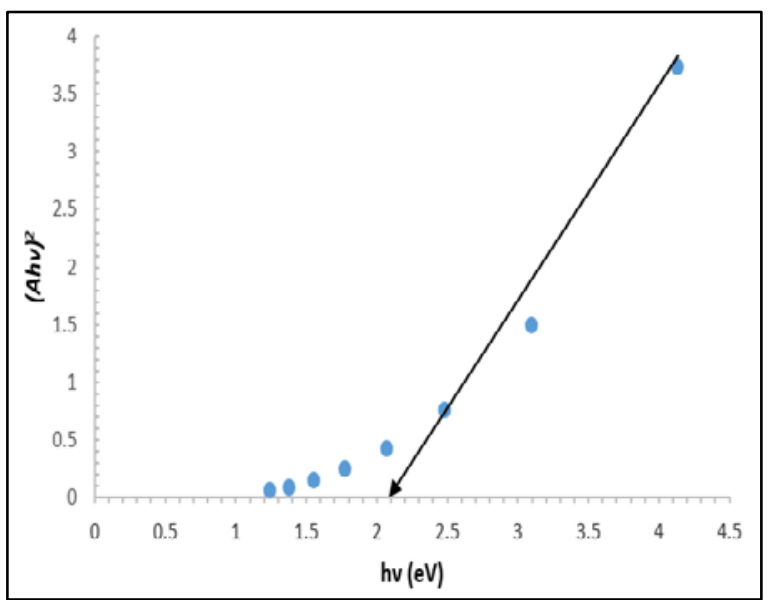

Figure 4: Curve (Ahv)2 against (hv) for the cobalt selenide thin films 
Based on the literature review, many researchers [45-51] have been used SILAR deposition method to produce various types of thin films. The obtained experimental results confirmed that the unique properties of thin films strongly depended on the experimental conditions including $\mathrm{pH}$, deposition times, deposition temperature, the number of immersion cycles, the presence of complexing agent and the nature of substrate.

\section{CONCLUSION}

The nanostructured cobalt selenide thin films have been deposited onto microscope glass slide successfully via SILAR deposition technique. The XRD results confirmed the existence of cobalt selenide films. The FESEM images indicated dense and smooth surface morphology of the obtained films. The band gap value was about $2.1 \mathrm{eV}$.

\section{ACKNOWLEDGMENT}

This research work was supported by INTI International University under INTI Internal Research Grant INTI -CAE-01-012018.

\section{Conflict of Interest: None}

\section{Source of Funding: None}

\section{REFERENCES}

1. Sara M, Khuram S, Shania S. Optical and structural properties of single source precursor based pure and Cu-doped antimony sulphide thin films by physical vapour deposition assisted technique. Chem. Phys. 2020; https://doi.org/10.1016/j.chemphys.2020.11 0979.

2. Saravanan N, Ho SM, Anuar K, Abdul A, Noraini K. Influence of the deposition time on the structure and morphology of the ZnS thin films electrodeposited on indium ton oxide substrates. Digest Journal of Nanomaterials and Biostructures. 2010; 5, 975-980.

3. Tan WT, Ho SM, Anuar K, Abdul H. Deposition and characterization of Cu4SnS4 thin films by chemical bath deposition method. Macedonian Journal of Chemistry and Chemical Engineering, 2010, 29, 97103.

4. Teoman O, Kavak H. Single step amperometric growth of CZTS thin film: Deposition current and stoichiometry relationship. Ceram. Int. 2021; 47: 2484124851.

5. Gwee SY, Ho SM, Tan WT, Anuar K. Influence of $\mathrm{pH}$ values on chemical bath deposited FeS2 thin films. Pacific Journal of Science and Technology, 2009, 10, 801805.

6. Fatima H, Annie P, Yuan C, Record M. Deposition of Sb2Se3 thin films on $\mathrm{Pt}$ substrate via electro-chemical atomic layer epitaxy (EC-ALE). J. Electroanal. Chem. 2020; https://doi.org/10.1016/j.jelechem.2020.114 774.

7. Hemdan S, Rabia M, Shaban M. Controlled synthesis of CdS nanoflowers thin films for H2 electro-generation. Mater. Sci. Semicond. Process. 2020; https://doi.org/10.1016/j.mssp.2020.105307.

8. Juan W, Chao L, Chen D, Sun C, Yang Z. Interlayered MoS2/rGO thin film for efficient lithium storage produced by electrospray deposition and far-infrared reduction. Appl. Surf. Sci. 2020; https://doi.org/10.1016/j.apsusc.2019.14394 0 .

9. Kinjal P, Shah V, Vipul K. Influence of deposition parameters and annealing on Cu2ZnSnS4 thin films grown by SILAR. J. Alloys Compd. 2015; 622: 942-947.

10. Saravanan N, Anuar K, Atan S, Ho SM. Chemical bath deposition of $\mathrm{ZnSe}$ thin films: SEM and XRD characterization. European Journal of Applied Sciences, 2011, 3, 113-116.

11. Haron J, Anuar K, Gwee SY, Ho SM, Tan WT. Preparation and characterization of PbSe thin films by chemical bath deposition. Jurnal Kimia, 2010, 4, 1-6.

12. Gong $\mathrm{X}$, Feng $\mathrm{M}, \mathrm{Wu} \mathrm{H}$, Zhou H, Suen $\mathrm{C}$, Zou H. Highly (100)-orientated SnSe thin films deposited by pulsed-laser deposition. Appl. Surf. Sci. 2021; https://doi.org/10.1016/j.apsusc.2020.14769 4.

13. Wang $\mathrm{X}, \mathrm{Yu} \mathrm{C}$, Wu J, Wei Z, Zhang $\mathrm{Y}$. Solvothermal Synthesis of Superhydrophobic ZnS Film. Asian J. Chem. 2013; 25: 1241-1243. 
14. Hillie T, Curren C, Swart H. ZnS thin films grown on $\mathrm{Si}(100)$ by $\mathrm{XeCl}$ pulsed laser ablation. Appl. Surf. Sci. 2001; 177: 73-77.

15. Sanchez T, Mathew $X$, Mathews R. Obtaining phase-pure CZTS thin films by annealing vacuum evaporated $\mathrm{CuS} / \mathrm{SnS} / \mathrm{ZnS}$ stack. J. Cryst. Growth. 2016; 445: 15-23.

16. Rondiya S, Rokade A, Sandesh J, Moses K. Synthesis of CdS thin films at room temperature by RF-magnetron sputtering and study of its structural, electrical, optical and morphology properties. Thin Solid Films. 2017; 631: 41-49.

17. Afrin S, Neal K, Raj S. Atomic layer Deposition of 2-dimensional, Semiconducting SnSe Thin Films. 2018 IEEE 13th Nanotechnology Materials and Devices Conference, 2019; DOI: 10.1109/NMDC.2018.8605911.

18. Anuar K, Lim KS, Ho SM, Saravanan N. SEM, EDAX and UV-visible studies on the properties of Cu2S thin films. Chalcogenide Letters, 2011, 8, 405-410.

19. Temesgen G, Abza T. Microstructural and Optical Characterization of Heterostructures of ZnS/CdS and CdS/ZnS Synthesized by Chemical Bath Deposition Method. Adv. Mater. Sci. Eng. 2020; https://doi.org/10.1155/2020/1401689.

20. Zulkefly K, Atan S, Ho SM, Anuar K, Tan WT. Preparation and studies of chemically deposited Cu4SnS4 thin films in the presence of complexing agent, Na2EDTA. Indian Journal of Engineering \& Materials Sciences, 2010, 17, 295-298.

21. Al-Bassam A. Electrodeposition of CuInSe2 thin films and their characteristics. Phys. B Condens. Matter. 1999; 266: 192-197.

22. Noraini K, Anuar K, HO SM, Saravanan N. XRD and AFM studies of ZnS thin films produced by electro deposition method. Arab. J. Chem. 2010; 3: 243-249.

23. Haron M, Ho SM, Saravanan N, Anuar K. Effect of deposition period and bath temperature on the properties of electrodeposited Cu4SnS4 films. Solid State Sci. Technol. 2009; 17: 226-237.

24. Zhang Y, Wang X, Chang C, Kedir M, Hao $S$, Chong $X$. Nanostructured copper sulfide thin film via a spatial successive ionic layer adsorption and reaction process showing significant surface-enhanced infrared absorption of CO2. J. Mater. Chem. C. 2020; 8: 3069-3078.
25. Shimaoka G, Suzuki Y, Arakawa T. Electron induced epitaxy of cubic ZnS on GaAs (100) surfaces. Appl. Surf. Sci. 2003; 212-213: 694-700.

26. Pati S, Banerji P, Majumder B. MOCVD grown $\mathrm{ZnO}$ thin film gas sensors: Influence of microstructure. Sens. Actuators A Phys. 2014; 213: 52-58.

27. Zaki M, Sava F, Nicu B, Galca A, Mihai C, Velea A. Synthesis and Characterization of Cu2ZnSnS4 Thin Films Obtained by Combined Magnetron Sputtering and Pulsed Laser Deposition. Nanomaterials, 2021; https://doi.org/10.3390/nano11092403.

28. Li J, Zou Y, Hu J, Wan L, Dong W. Optoeletronic investigation of $\mathrm{Cu} 2 \mathrm{ZnSn}(\mathrm{S}, \mathrm{Se}) 4$ thin-films \& $\mathrm{Cu} 2 \mathrm{ZnSn}(\mathrm{S}, \mathrm{Se}) 4 / \mathrm{CdS}$ interface with scanning probe microscopy. Sci. China Chem. 2016; 59: 231-236.

29. Davide B. Alberto G, Trevor S, Eugenio T. Analysis of Nanocrystalline ZnS Thin Films by XPS. Surf. Sci. Spectra, 2003; https://doi.org/10.1116/11.20030117.

30. Saeed M, Riaz S, Naseem S. Optical Properties of Sol-gel Deposited ZnS Thin Films: Spectroscopic Ellipsometry. Mater. Today Proc. 2005; 2: 5497-5503.

31. Pathan H, Lokhande D. Deposition of metal chalcogenide thin films by successive ionic layer adsorption and reaction (SILAR) method. Bull. Mater. Sci. 2004; 27: 85-111.

32. Laukaitis G, Lindroos S, Rackaitis $M$, Leskela M. SILAR deposition of CdxZn1xS thin films. Appl. Surf. Sci. 2000; 161: 396-405.

33. Samantha P, Della G, Ren J, Elena C, Martucci A. SILAR Deposition of Metal Oxide Nanostructured Films. Nano Micro Small, 2021; https://doi.org/10.1002/smll.202101666.

34. Sartale S, Lokhande D. Preparation and characterization of nickel sulphide thin films using successive ionic layer adsorption and reaction (SILAR) method. Mater. Chem. Phys. 2001; DOI:10.1016/S0254-0584(01)00314-5.

35. Hua S, Mu J. SILAR Deposition of CdS Thin Films on Glass Substrates Modified with 3-Mercaptopropyltrimethoxysilane. J. Dispers. Sci. Technol. 2005; DOI:10.1081/DIS-200063026.

36. Betil G, Saglam M, Ates A. Effects of SILAR cycle on the electrical characteristics 
of $\mathrm{Cd} / \mathrm{CdSe} / \mathrm{n}-\mathrm{Si} / \mathrm{Au}-\mathrm{Sb}$ structure. Turk. J. Phys. 2011; 35: 1-12.

37. https://www.statista.com/statistics/339759/g lobal-cobalt-mine-production/

38. https://www.statista.com/statistics/600410/r efinery-production-worldwide-of-selenium

39. Osvaldo N, Luzia D, Fabio D, Ferreira J. Nano characterization techniques. Norwich: William Andrew; 2017.

40. Zishan H. Emerging Trends in Nanotechnology. Basingstoke: Springer Nature; 2021.

41. Yoshio W, Eiichiro M, Kozo S. X-ray diffraction crystallography: Introduction, examples and solved problems. Berlin: Springer Science \& Business Media; 2011.

42. Manisha A, Satya P. Engineering chemistry. Concepts in chemistry for engineering. 2nd edition. India: Khanna Publishing House; 2018.

43. Bhim P. Chemical Analysis and Material Characterization by Spectrophotometry. Amsterdam: Elsevier; 2019.

44. Perkampus, H. UV-VIS Spectroscopy and Its Applications. Berlin: Springer Sciences \& Business Media; 2013.

45. Tuba C. Study of the physical properties of CuS thin films grown by SILAR method. Opt. Quantum Electron. 2019; https://doi.org/10.1007/s11082-019-1963-0.

46. Ahmet T, Emin M, Harun G. Fe doping effects in MgO thin films grown with SILAR technique. Mater. Chem. Phys.
2021;

https://doi.org/10.1016/j.matchemphys.2021 .124993.

47. Ashith V, Rao K. Structural and Optical Properties of ZnS Thin Films by SILAR Technique obtained by acetate Precursor. IOP Conf. Ser. Mater. Sci. Eng. 2018; https://doi.org/10.1088/1757899X/360/1/012058.

48. Çayır T. Effect of different thickness and solution concentration on CuS thin film grown by SILAR method. J. Sci. Perspect. 2019; 3: 207-214. DOI: 10.26900/jsp.3.021.

49. Deshpande M, Krishna C, Patel N, Bhoi R. Study of Sb2S3 thin films deposited by SILAR method. Mater. Res. Express, 2018; https://doi.org/10.1088/2053-1591/aac4ef.

50. Ubale U, Mitkari A. Thickness Dependent Physical Properties of SILAR Deposited Nanostructured CoS Thin Films. ES Mater. Manuf. 2019; 5: 49-56.

51. Harshad D, Vanita S, Amar M, Jin H. Facile synthesis of Cu2SnS3 thin films grown by SILAR method: effect of film thickness. J. Mater. Sci. Mater. Electron. 2017; 28: 79127921. (2017).

How to cite this article: Ho Soonmin. Properties study of SILAR deposited cobalt selenide thin films. International Journal of Research and Review. 2021; 8(12): 119-124. DOI: https:// doi.org/10.52403/ijrr.20211216 